\title{
Diffusion of Cu Ions into Nanoclay by Molten Salt Ion Exchange for Antibacterial Application
}

\author{
Afsaneh Nouri, Mohammad Ghorbanpour* and Samaneh Lotfiman \\ Chemical Engineering Department, University of Mohaghegh Ardabili, \\ P.O. Box 56199-11367 Ardabil, Iran \\ ${ }^{*}$ Corresponding author: ghorbanpour@uma.ac.ir
}

Published online: 25 April 2018

To cite this article: Nouri, A., Ghorbanpour, M. \& Lotfiman, S. (2018). Diffusion of Cu ions into nanoclay by molten salt ion exchange for antibacterial application. J. Phys. Sci., 29(1), 31-42, https://doi.org/10.21315/jps2018.29.1.3

To link to this article: https://doi.org/10.21315/jps2018.29.1.3

\begin{abstract}
Novel Cu/nanoclay composites with antibacterial activity were synthesised by molten salt ion exchange method at two temperatures and at different times. The produced composites were characterised using X-ray diffraction (XRD), diffuse reflectance spectroscopy (DRS), X-ray fluorescence (XRF) and scanning electron microscopy (SEM). The antibacterial activity of these composites was assayed by the disc inhibition method. XRD patterns indicate that nanoclay has a d-spacing $(1.44 \mathrm{~nm})$, higher than Cu/nanoclay composites (1.34-1.37 nm). This result implies that copper nanoparticles could exist in microspores of nanoclay. On the other hand, the UV-Vis findings confirm that no copper in the form of sulfate existed in the obtained composites. The antibacterial activity of $\mathrm{Cu} /$ nanoclay nanocomposites against Escherichia coli and Staphylococcus aureus showed efficient bactericidal effect. On the other hand, results demonstrate that the antibacterial activity of the resultant composites does not depend on ion exchange time and temperature. Thus, the resultant composites show high stability that can last for a long time. The produced composites by this novel method can be used to synthesise nanoclay composite with antibacterial activity for various applications such as water treatment and biodegradable composites.
\end{abstract}

Keywords: $\mathrm{Cu}$ /nanoclay composites, antibacterial, molten salt ion exchange, $\mathrm{Cu}$ diffusion, disc inhibition

\section{INTRODUCTION}

Many millions of people worldwide affected by infectious diseases each year face risks of death, disability, and social and economic disturbance. Antibiotic 
resistance and poor progress in the development of new antibacterial agents compound these circumstances. Scientists seeking other research methods have recognised that metals, essential to life, could be useful in new developmental pathways in the antibacterial war. Metals can function as abiotic microbicides, affecting microorganisms' growth, morphology and biochemical activities. Compounds of metals, especially those with silver, copper and zinc, can be formed into the metal-based nanoparticles. ${ }^{1-8}$ Such metal ions or metal compounds are utilised in biomedical and environmental applications, including microbicides for preventing or fighting infections. Inorganic antimicrobial agents also display safety and stability, important characteristics not found in organic antimicrobial agents. ${ }^{9}$

Copper and its complexes are widely used in sterilising liquids and textiles, and have been factors in human tissues for centuries. Copper nanoparticles are attractive for their characteristics: stability, robustness and longer shelf life compared with organic antimicrobial agents. Therefore, copper is sometimes utilised in water purification and in inactivation of some microorganisms and bacteria. Interestingly, human tissues are barely responsive to copper, but microorganisms show high copper sensitivities. ${ }^{1,10}$ It is thought that the antimicrobial action of these nanoparticles comes from their scale, which is small and thus has high surface area to volume ratio. Consequently, it reacts to bacterial membranes, instead of the interaction related uniquely to the metal ions' discharge. Through Fenton and Haber-Weiss reactions, copper ions catalyse reactions that generate hydroxyl radicals and ultimately cause oxidative damage to lipids, proteins and DNA. ${ }^{11,12}$

However, there are limitations to the therapeutic use of copper nanoparticles, which are unstable in air and cytotoxic in high concentrations. One solution is to create a platform of minerals layered like clay for the nanoparticles. ${ }^{13-16}$ This protects the particles from oxidation, and ensures slow release, leading to greater efficacy. Furthermore, biocompatibility is enhanced, since clays and nanoparticles-clay composites are inherently nontoxic to the environment. ${ }^{6,8,17}$ Consequently, clay minerals are an economical, complementary therapeutic solution for topical bacterial infections. Clay minerals possess a net negative charge, facilitating exchange of positively charged ions on their surface. Clay minerals' physical properties are a component in many therapeutic products, serving as a carrier of antibacterial agents or as a means of eliminating toxic substances from the body. ${ }^{3}$ Clay-based antimicrobials exist as drugs, small organic molecules and nanoparticles. Higher protection and efficacy are obtainable provided the nanoparticles are introduced into the clay mineral's layer and are also adsorbed on the outer places. Embedded nanoparticles resist agglomeration better and have enhanced protection compared with surface absorbed particles. ${ }^{17}$ To date, $\mathrm{Cu}$ /clay composites have been usually produced by sol gel coating and ion exchange treatment. ${ }^{10,16-20}$ Ion exchange 
treatment has some benefits over other methods, as a result of its straightforward procedure and lesser expense. Consequently, research on antibacterial clay minerals has been conducted mostly on ion-exchanged clays. ${ }^{13,15-19}$

In this study, our team introduces another approach in ion exchange, namely, molten salt ion exchange. This is a diffusion method; alkali ions of clay (primarily sodium or calcium) are replaced by copper ions present in molten salt. As a result, copper enters the clay structure as $\mathrm{Cu}^{+}$ions. To the best of our knowledge, the present report is the first to describe molten salt ion exchange of copper with nanoclay.

\section{EXPERIMENTAL}

\subsection{Materials}

Nanoclay montmorillonite, $\mathrm{k}_{10}$, used as a solid support for copper, was obtained from Sigma-Aldrich (Tehran, Iran). Nutrient agar was purchased from Merck (Tehran, Iran). The bacterial strains used for the antibacterial activity were gramnegative E. coli (PTCC 1270) and gram-positive S. aureus (PTCC 1112), obtained from the Iranian Research Organization for Science and Technology (Tehran, Iran). All reagents were analytical grade and used without further refinement.

\subsection{Molten Salt Ion Exchange with Copper}

The molten salt ion exchange process began with immersion of nanoclay into $\mathrm{CuSO}_{4} \cdot 5 \mathrm{H}_{2} \mathrm{O}$ at $450^{\circ} \mathrm{C}$ and $550^{\circ} \mathrm{C}$ for $1,2,3$ and $5 \mathrm{~min}$. This step was conducted using $1 \mathrm{~g}$ of nanoclay and $1 \mathrm{~g}$ of $\mathrm{CuSO}_{4} \cdot 5 \mathrm{H}_{2} \mathrm{O}$. After ion exchange, the nanoclay was adequately washed with distilled water and sonication. After filtration, the composites were dried in an oven at $25^{\circ} \mathrm{C}$.

\subsection{Characterisation Methods}

\subsubsection{SEM}

The morphology of samples was observed with a scanning electron microscope (SEM) (LEO 1430VP, Germany).

\subsubsection{XRD}

X-ray diffraction (XRD) patterns were recorded using a Philips PW 1050 diffractometer (Netherlands). Samples in powder form were pressed in a rotational holder. Reflection mode was used for all measurements. 


\subsubsection{DR UV-Vis}

UV-Vis diffuse reflectance spectroscopy (DR UV-Vis) was used for a qualitative description of the differences in absorbance depending on the amount of $\mathrm{ZnO}$ in the studied composites. DR UV-Vis of the powder samples was conducted in a $5.0 \mathrm{~mm}$ quartz cell registered in the wavelength range of $200-800 \mathrm{~nm}$ using a spectrophotometer (Scinco S4100, South Korea).

\subsection{Leaching Tests}

In order to evaluate the stability of the composites, leaching tests were performed. For each composite material, $0.2 \mathrm{~g}$ was immersed in $10 \mathrm{ml}$ of distilled water and vigorous shaken in a shaking water bath $\left(30^{\circ} \mathrm{C}, 200 \mathrm{rpm}\right)$ for $24 \mathrm{~h}$. Supernatants from each test tube were collected by centrifugation at $4000 \mathrm{rpm}$ for $10 \mathrm{~min}$. Copper ions released from composites were qualitatively determined by atomic absorption spectroscopy analysis (Varian/AAS, 20BQ, USA).

\subsection{Antibacterial Activity}

The antibacterial activity of the $\mathrm{Cu}$ /nanoclay composites against both $E$. coli (gram-negative) and $S$. aureus (gram-positive) was tested by agar diffusion test. Samples were exposed to bacteria in solid media (nutrient agar), and the inhibition zone around each sample was measured and recorded as the antibacterial effect of copper nanoparticles. Agar plates were inoculated with $100 \mu 1$ suspensions of bacteria. Composites were placed on $0.5 \mathrm{~cm}$ diameter agar disks and incubated at $37^{\circ} \mathrm{C}$ for $24 \mathrm{~h}$. The inhibition zone for bacterial growth was detected visually (shown later in Figures 5 and 6).

\section{RESULTS AND DISCUSSION}

\subsection{Ion Exchange Treatment of Nanoclay}

Immersing the nanoclays in the molten $\mathrm{CuSO}_{4}$ causes the replacing of $\mathrm{Cu}^{2+}$ in the molten salt with the cations in the nanoclay. Therefore, the nanoclays' interlayer spaces can serve as a support for transition metal-nanoparticle synthesis and as an adsorptive layer for cation diffusion. The parent nanoclay subjected to this ion exchange was cream-coloured. As shown in Figure 1, after alkaline ion exchange the colour of nanoclay changed to russet. Obviously, increments of temperature and processing time created this colour change. Ueda et al. investigated molten salt ion exchange of $\mathrm{Tl}$ ions into glass at $753 \mathrm{~K}$ during lengths of time. ${ }^{21}$ They stated 
that the spread of Ti ions from the outer to inner layers of glass limits the process of the ion exchange. ${ }^{21}$ Therefore, this colour variance is related to the loading amount of copper ions into the clays' structure.

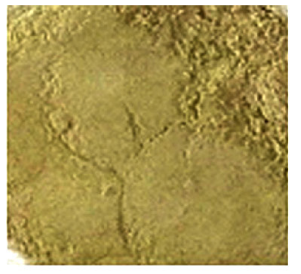

(a)

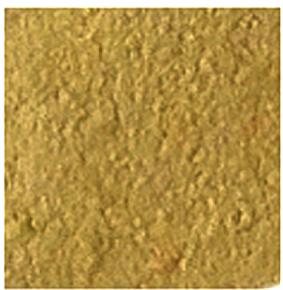

(e)

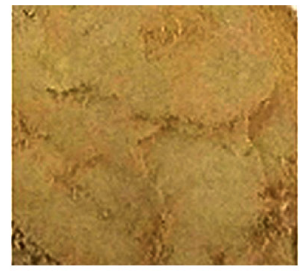

(b)

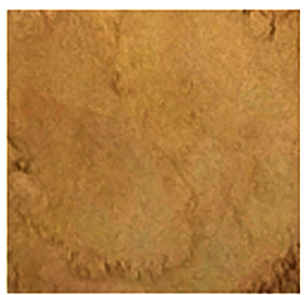

(f)

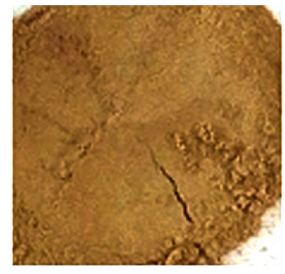

(c)

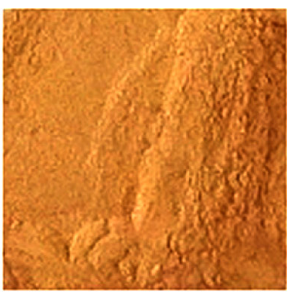

$(\mathrm{g})$

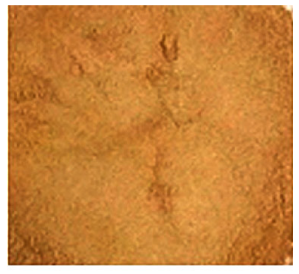

(d)

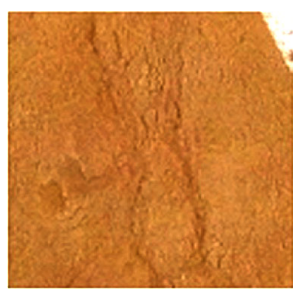

(h)

Figure 1: Photographs of ion-exchanged nanoclays at $450^{\circ} \mathrm{C}$ for $1 \mathrm{~min}(\mathrm{a}), 2 \mathrm{~min}(\mathrm{~b})$, $3 \min (\mathrm{c})$ and $5 \min (\mathrm{d})$; and at $550^{\circ} \mathrm{C}$ for $1 \mathrm{~min}(\mathrm{e}), 2 \mathrm{~min}(\mathrm{f}), 3 \mathrm{~min}(\mathrm{~g})$ and $5 \min (\mathrm{h})$.

\subsection{SEM Analysis}

The SEM graph of the parent nanoclay (Figure 2a) displays the typical flat structure. The ion-exchanged samples have a layered structure with several nano-sized flake particles with layer morphology. Obviously, this process increased the porosity. On the other hand, pore sizes tend to be enhanced by increasing temperature and processing time. This is due to an increase in the interplanar spacing of nanoclays, with some copper ions intercalated into the layers, comprising a significant fraction of pore spaces. ${ }^{1,6,7}$

\subsection{XRD Analysis}

$\mathrm{XRD}$ patterns of the parent nanoclays and nanocomposites prepared by the alkaline ion exchange method at $450^{\circ} \mathrm{C}$ and $550^{\circ} \mathrm{C}$ in the $2 \theta$ range of $4^{\circ}-60^{\circ}$ are shown in Figure 3. The XRD pattern of the natural clay determined a montmorillonite with a (001) interlayer spacing of $1.44 \mathrm{~nm}$. After ion exchange, the original d spacing in the montmorillonite clay decreased to $1.34 \mathrm{~nm}$ for $1 \mathrm{~min}$ at $450^{\circ} \mathrm{C}$ due to the water lost in the interlayers. Also, the diffractograms showed more differences. 


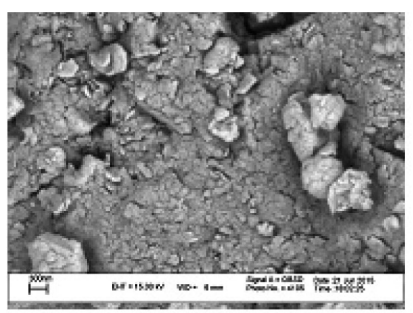

(a)

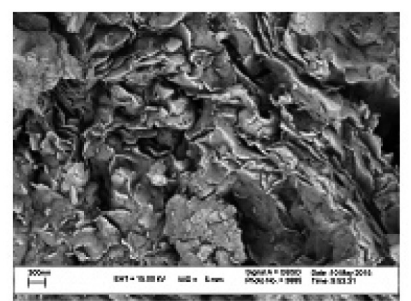

(d)

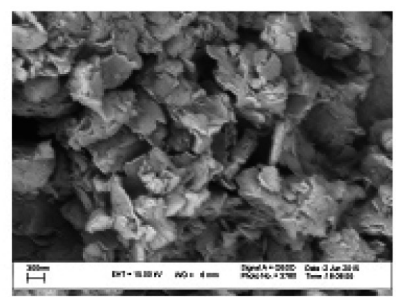

(g)

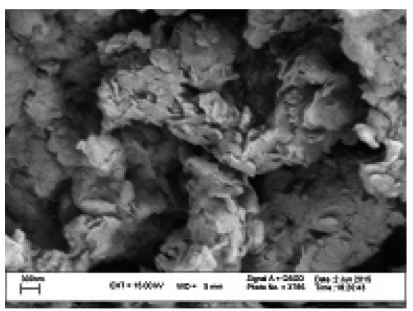

(b)

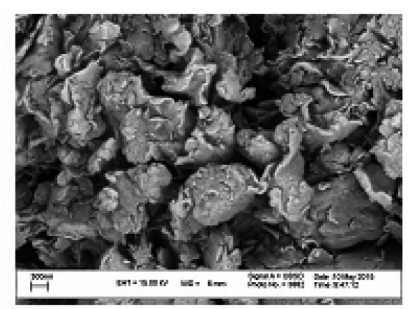

(e)

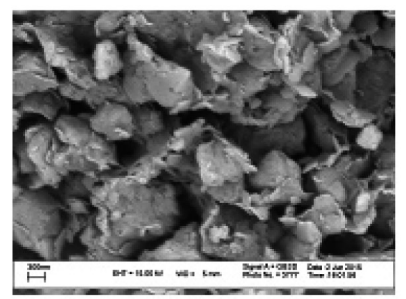

(h)

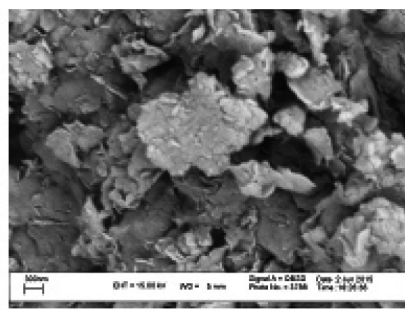

(c)

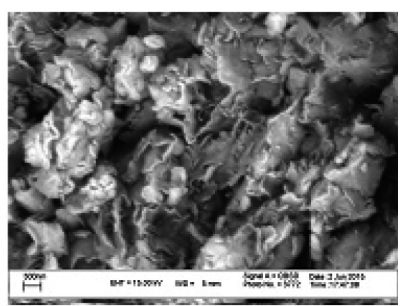

(f)

Figure 2: SEM images of parent nanoclays (a); ion-exchanged nanoclays at $450^{\circ} \mathrm{C}$ for $1 \mathrm{~min}(\mathrm{~b}), 2 \mathrm{~min}$ (c), $3 \mathrm{~min}(\mathrm{~d})$ and $5 \mathrm{~min}(\mathrm{e})$; and at $550^{\circ} \mathrm{C}$ for $1 \mathrm{~min}$ (f), $3 \mathrm{~min}$ $(\mathrm{g})$ and $5 \mathrm{~min}(\mathrm{~h})$.

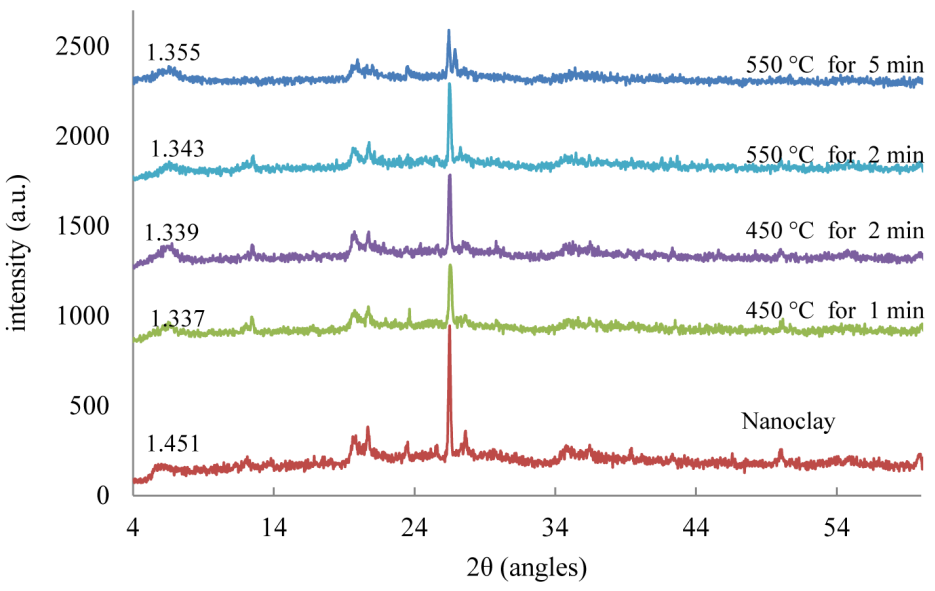

Figure 3: The XRD patterns of $\mathrm{Cu} /$ nanoclay composites. 
By enhancing the temperature and time, the $d$-spacing of interlayers increased and reached $1.37 \mathrm{~nm}$ for $5 \mathrm{~min}$ at $550^{\circ} \mathrm{C}$. The SEM images also show the expanded layers. It has been also reported that high temperature affected the interlayer structure. ${ }^{22}$ Therefore, interplanar spacing of nanoclays support more places for aggregation the exchanged ions. On the other hand, the peaks of montmorillonite and Quartz in ion-exchange samples became broader and less intense. The existence of intercalated $\mathrm{Cu}^{2+}$ was identified by changing in the $d$-spacing position and shape differences of the (001) reflection. ${ }^{10,17}$ Furthermore, no peaks belonging to the impurities were observed, indicating the high purity of the produced samples.

\subsection{UV-Vis Spectra}

The UV-Vis diffuse reflectance spectra of nanoclay matrix and $\mathrm{Cu} /$ nanoclay are shown in Figure 4. The traces show two broad peaks located at 313 and $438 \mathrm{~nm}$. These bands correspond to a charge transfer transition of interlayer tetrahedral and octahedral atoms. Furthermore, copper sulfate powder spectra show two absorption peaks at 305 and $245 \mathrm{~nm}$. These peaks disappeared clearly after ion exchange. This confirms that no copper in the form of sulfate existed in the obtained composites. The absorption spectra for $\mathrm{Cu} /$ nanoclay composites show absorption peaks at 355 and $430 \mathrm{~nm}$ with an absorption edge at $316 \mathrm{~nm}$. The maximum absorbance of nanocomposites around $355 \mathrm{~nm}$ was slightly blue shifted by increasing the time and temperature of process. Consequently, the band gap related to these samples was slightly elevated. This may be attributed to quantum confinement effects, the changes in composite structure and also the connection form of loaded copper ions. $^{23}$

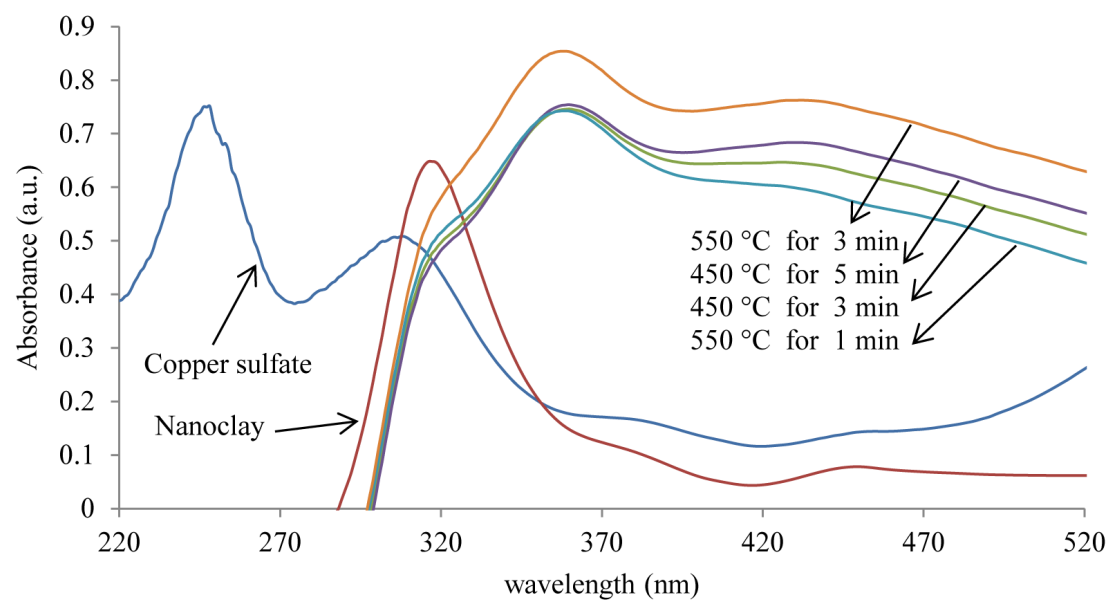

Figure 4: Diffuse reflectance spectra of samples. 


\subsection{Copper Ion Release Assay}

The results showed that increasing the time and temperature of ion exchange did not affect reasonably on the concentration of copper in the solution (Table 1). The release of copper ions occurred in a range between 3.7-6.2 ppm. The source of the released $\mathrm{Cu}^{2+}$ might be from absorbed nanoparticles on the clay surface, or they may have come from the suspended ions in the solution after desorption.

Table 1: Copper concentration in water at different contact times between $\mathrm{Cu} /$ nanoclay nanocomposite and aqueous media.

\begin{tabular}{ccc}
\hline $\begin{array}{c}\text { Ion exchange } \\
\text { temperature }\left({ }^{\circ} \mathrm{C}\right)\end{array}$ & $\begin{array}{c}\text { Ion exchange } \\
\text { time }(\mathrm{min})\end{array}$ & $\begin{array}{c}\text { Copper concentration } \\
(\mathrm{ppm})\end{array}$ \\
\hline 450 & 1 & $3.71 \pm 0.7$ \\
& 3 & $4.50 \pm 1.1$ \\
550 & 5 & $6.21 \pm 1.7$ \\
& 1 & $5.59 \pm 0.4$ \\
& 3 & $4.29 \pm 1.1$ \\
& 5 & $5.15 \pm 1.5$ \\
\hline
\end{tabular}

\subsection{Antibacterial Assay}

The antibacterial properties of $\mathrm{Cu} /$ nanoclay composites were tested comparatively against gram-negative $E$. coli and gram-positive $S$. aureus bacteria by disk diffusion test. The inhibition zone for bacterial growth under and around the tested samples was detected visually (Figure 6). The data were listed in Table 2. The results of the antibacterial activity tests indicate that nanoclay is ineffective against both $E$. coli and $S$. aureus. However, the antibacterial activity of $\mathrm{Cu} /$ nanoclay tested on $E$. coli and $S$. aureus showed positive results. The results showed that the antibacterial efficiency of the composites was not influenced by the time or temperature of ion exchange process. This can be validated by diffusion theory, which states that the surface sodium ions of nanoclay were the first ions exchanged with copper ions. These copper ions are responsible for the antibacterial activity of composites. With longer processing time for exchange, the sodium of the nanoclay inner layer starts exchanging with copper ions. These copper ions have no effect on the antibacterial activity of composites. Thus, it can be concluded that after $1 \mathrm{~min}$, the surface of nanoclay was saturated with copper ions, and that this amount of time is sufficient for obtaining the maximum antibacterial effect.

Antibacterial activity is affected by bacterial type. In $\mathrm{Cu} /$ nanoclay, E. coli was found to be more influenced to growth inhibition than $S$. aureus. The antibacterial 
properties of copper ions were well studied, as was the mechanism of their actions. The function of this property was generally stated and the mixture of some types of interactions, such as membrane perforation, DNA damage and protein denaturation, were reported. However, not all microorganisms display equal antibacterial activity through these interactions. Researchers have documented that the kind and size of nanoparticles, the strain and concentration of bacterial as well as the nature of growth media affected bacterial sensitivity of nanoparticles. ${ }^{17}$

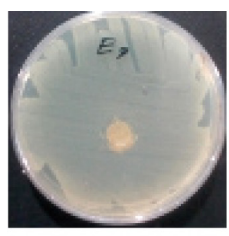

(a)

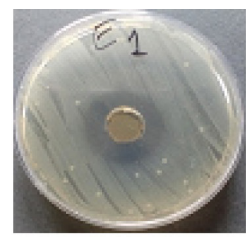

(b)

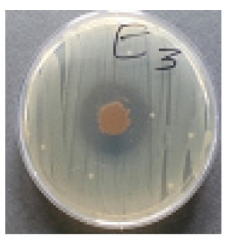

(c)

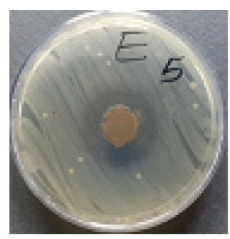

(d)

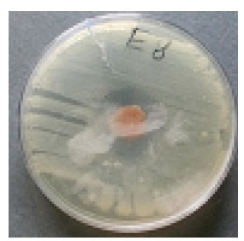

(e)

Figure 5: Inhibition zone of parent nanoclay (a); ion-exchanged nanoclay at $450^{\circ} \mathrm{C}$ for $1 \mathrm{~min}(\mathrm{~b})$ and $3 \mathrm{~min}(\mathrm{c})$; and at $550^{\circ} \mathrm{C}$ for $1 \mathrm{~min}(\mathrm{~d})$ and $3 \mathrm{~min}$ (e) against E. coli.

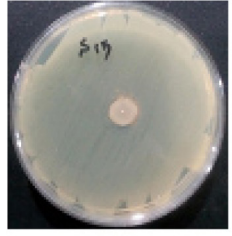

(a)

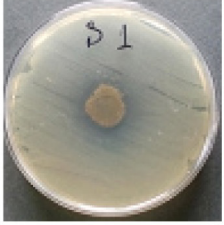

(b)

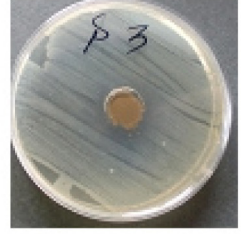

(c)

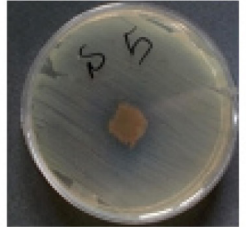

(d)

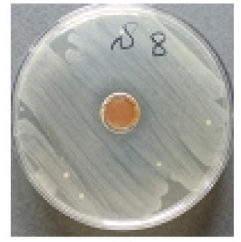

(e)

Figure 6: Inhibition zone of parent nanoclay (a); ion-exchanged nanoclay at $450^{\circ} \mathrm{C}$ for $1 \mathrm{~min}(\mathrm{~b})$ and $3 \mathrm{~min}(\mathrm{c})$; and at $550^{\circ} \mathrm{C}$ for $1 \mathrm{~min}(\mathrm{~d})$ and $3 \mathrm{~min}(\mathrm{e})$ against S. aureus.

Table 2: The diameter of inhibition zone for different samples.

\begin{tabular}{cccc}
\hline \multirow{2}{*}{ Temperature $\left({ }^{\circ} \mathrm{C}\right)$} & Time $(\min )$ & \multicolumn{2}{c}{ Inhibition zone $(\mathrm{mm})$} \\
\cline { 3 - 4 } & & E. coli & S. aureus \\
\hline 450 & 1 & $7.74 \pm 1.9$ & $4.52 \pm 1.5$ \\
& 2 & $7.33 \pm 1.5$ & $5.6 \pm 1.6$ \\
3 & $8.09 \pm 1.6$ & $4.9 \pm 1.7$ \\
550 & 5 & $7.90 \pm 1.7$ & $4.86 \pm 2.2$ \\
& 1 & $8.14 \pm 1.3$ & $5.3 \pm 2.3$ \\
& 2 & $9.26 \pm 2.3$ & $4.7 \pm 1.6$ \\
& 3 & $9.46 \pm 1.6$ & $5.3 \pm 2.5$ \\
& 5 & $8.26 \pm 2.2$ & $5.2 \pm 1.9$ \\
\hline
\end{tabular}


The presence of carboxylates as functional groups in the cell walls of viable bacteria is usually negatively charged. Given the electrostatic force, bacteria are enticed to $\mathrm{Cu}^{2+}$-montmorillonite and immobilised on the surface. Furthermore, $\mathrm{Cu}$ ions can also disconnect and discharge its antimicrobial effect, which influences the dispersed bacteria.

On the other hand, direct contact of the coated $\mathrm{Cu}^{2+}$ on the surface with bacterial membrane may also prevent bacterial action. Hence, the antibacterial activity of $\mathrm{Cu}^{2+}$-montmorillonite was supported significantly by the montmorillonite clay matrix as a stable carrier for the nanoparticles. However, the frequent contact with the bacterial membrane enhanced. Further $\mathrm{Cu}^{2+}$ released from the composite may also independently restrict the bacterial cells. As the results showed the amount of the released $\mathrm{Cu}$ ions in the medium is much less than its density on the montmorillonite surface (recall the results of the release tests), so, the antimicrobial capability of the doped $\mathrm{Cu}^{2+}$ might dominate compared to the discharged $\mathrm{Cu}^{2+}$ cations into the medium. ${ }^{10,16,17}$ Our results are in line with the findings stated by Malachova et al. using framework structures in which $\mathrm{Ag}, \mathrm{Cu}$ and $\mathrm{Zn}$ were exchanged with Namontmorillonite interchanged with silver and copper and zinc. ${ }^{22}$

\section{CONCLUSION}

In the present work, bactericidal activity of copper ions exchanged with the interlayer of nanoclay was investigated against $E$. coli and $S$. aureus. Lattice parameters, diffuse reflectance spectroscopy and antibacterial activity of nanocomposites were examined using a variety of characterisation techniques. XRD patterns indicate that copper nanoparticles could exist in microspores of nanoclay. The antibacterial activity of $\mathrm{Cu} /$ nanoclay nanocomposites against $E$. coli showed efficient bactericidal effect. On the other hand, the results demonstrate that the antibacterial activity of the resultant composites does not depend on ion exchange time and temperature. Furthermore, the resultant composites show high stability that can last for a long time. These novel composites have a wide range of applications in production of nanoclay-based materials in which their antibacterial activity is important.

\section{REFERENCES}

1. Pourabolghasem, H. et al. (2016). Antibacterial activity of copper-doped montmorillonite nanocomposites prepared by alkaline ion exchange method. J. Cent. South Uni., 23, 787-792, http://dx.doi.org/10.21315/jps2016.27.2.1. 
2. Top, A. \& lku, S. U. (2004). Silver, zinc, and copper exchange in a Naclinoptilolite and resulting effect on antibacterial activity. Appl. Clay Sci., 27, 13-19, https://doi.org/10.1016/j.clay.2003.12.002.

3. Payami, R., Ghorbanpour, M. \& Parchehbaf Jadid, A. (2016). Antibacterial silver-doped bioactive silica gel production using molten salt method. J. Nanostruct. Chem., 6(3), 215-221, https://doi.org/10.1007/s40097-0160193-2.

4. Lotfiman, S. \& Ghorbanpour, M. (2017). Antimicrobial activity of ZnO/silica gel nanocomposites prepared by a simple and fast solid-state method. Surf. Coat. Tech., 310, 129-133, https://doi.org/10.1016/j.surfcoat.2016.12.032.

5. Moghimi, M., Ghorbanpour, M. \& Lotfiman, S. (2017). Silica-supported copper oxide nanoleaf with antimicrobial activity against Escherichia coli. J. Water Environ. Nanotechnol., 2(2), 112-117, https://doi.org/10.22090/ jwent.2017.02.006.

6. Pourabolghasem, H., Ghorbanpour, M. \& Shayegh, R. (2016). Antibacterial activity of copper-doped montmorillonite nanocomposites prepared by alkaline ion exchange method. J. Phys. Sci., 27(2), 1-12, http://dx.doi. org/10.21315/jps2016.27.2.1.

7. Ghorbanpour, M., Nouri, A. \& Lotfiman, S. (2018). Preparation of zinc oxide-nanoclay hybrids by alkaline ion exchange method. Braz. J. Chem. Eng., forthcoming.

8. Gilani, S., Ghorbanpour, M. \& Parchehbaf Jadid, A. (2016). Antibacterial activity of $\mathrm{ZnO}$ films prepared by anodizing. J. Nanostruct. Chem., 6(2), 183-189, http://dx.doi.org/10.1007/s40097-016-0194-1.

9. Wilczynski, M. (2000). Antimicrobial porcelain enamels. Ceram. Eng. Sci. Proc., 21, 81-83, http://dx.doi.org/10.1002/9780470294642.ch11.

10. Sohrabnezhad, S. H., Mehdipour Moghaddam, M. J. \& Salavatiyan, T. (2014). Synthesis and characterization of CuO-montmorillonite nanocomposite by thermal decomposition method and antibacterial activity of nanocomposite. Spectrochim. Acta Mol. Biomol., 125, 73-78, http://dx.doi.org/10.1016/j. saa.2014.01.080.

11. Halliwell, B. \& Gutteridge, J. M. (1990). Role of free radicals and catalytic metal ions in human disease: An overview. Methods Enzymol., 186, 1-85.

12. Imlay, J., Chin, S. \& Linn, S. (1988). Toxic DNA damage by hydrogen peroxide through the Fenton reaction in vivo and in vitro. Sci., 240, 640-642.

13. Ohashi, F. \& Oya, A. (1992). Antimicrobial and antifungal agents derived from clay minerals (II). Appl. Clay Sci., 6, 301-311, http://dx.doi. org/10.1007/BF00360741.

14. Onodera, Y. et al. (2001). Bactericidal allophonic materials prepared from allophane soil: Bactericidal activities of silver/phosphorus-silver-loaded allophonic specimens. Appl. Clay Sci., 18, 135-144. 
15. Rivera-Garza, M. et al. (2000). Silver supported on natural Mexican zeolite as an antibacterial material. Microp. Mesop. Mater., 39, 431-444, https://doi.org/10.1016/S1387-1811(00)00217-1.

16. Zhou, Y. et al. (2004). Antimicrobial ability of $\mathrm{Cu}^{2+}$-montmorillonite. Appl. Clay Sci., 27, 215-221, https://doi.org/10.1016/j.clay.2004.06.002.

17. Bagchi, B. et al. (2013). In situ synthesis and antibacterial activity of copper nanoparticle loaded natural montmorillonite clay based on contact inhibition and ion release. Coll. Surf. B, 108, 358-365, http://dx.doi.org/10.1016/j. colsurfb.2013.03.019.

18. Drelich, J. et al. (2011). Vermiculite decorated with copper nanoparticles: Novel antibacterial hybrid material. Appl. Surf. Sci., 257, 9435-9443, http://dx.doi.org/10.1016/j.apsusc.2011.06.027.

19. Hu, C. H., Xu, Z. R. \& Xia, M. S. (2010). Antibacterial effect of $\mathrm{Cu}^{2+}-$ exchanged montmorillonite on Aeromonashydrophila and discussion on its mechanism. Vet. Microbiol., 109, 83-88, http://dx.doi.org/10.1016/j. vetmic.2005.04.021.

20. Ma, Y. L., Yang, B., Guo, T. \& Xie, L. (2016). Antibacterial mechanism of $\mathrm{Cu}^{2+}-\mathrm{ZnO} /$ cetylpyridinium-montmorillonite in vitro. Appl. Clay Sci., 50, 348-353, http://dx.doi.org/10.1016/j.clay.2010.08.025.

21. Ueda, M. et al. (2012). Diffusion of $\mathrm{Tl}$ ions into glass treated by molten salt ion exchange and hydrogen reduction. Mater. Trans., 53, 575-577, http://dx.doi.org/10.2320/matertrans.M2011343.

22. Malachova, K. et al. (2011). Antibacterial and antifungal activities of silver, copper and zinc montmorillonites. Appl. Clay Sci., 53, 642-645, https://doi. org/10.1016/j.clay.2011.05.016.

23. Jalil, A.A. et al.(2013). Tailoring the current density to enhance photocatalytic activity of $\mathrm{CuO} / \mathrm{HY}$ for decolorization of malachite green. J. Electroanal. Chem., 701, 50-58, http://dx.doi.org/10.1016/j.jelechem.2013.05.003. 